OPEN ACCESS

Edited by:

Jin Eun Yoo,

Korea National University

of Education, South Korea

Reviewed by:

Silvia Testa

Università degli Studi di Torino, Italy

Hugo Carretero-Dios,

Universidad de Granada, Spain

${ }^{*}$ Correspondence: Yee Cheng Kueh yckueh@usm.my

Specialty section:

This article was submitted to

Quantitative Psychology

and Measurement,

a section of the journal

Frontiers in Psychology

Received: 19 December 2017 Accepted: 08 June 2018

Published: 03 July 2018

Citation:

Kueh YC, Abdullah N, Kuan G,

Morris T and Naing NN (2018) Testing Measurement and Factor Structure

Invariance of the Physical Activity and Leisure Motivation Scale for Youth Across Gender. Front. Psychol. 9:1096.

doi: 10.3389/fpsyg.2018.01096

\section{Testing Measurement and Factor Structure Invariance of the Physical Activity and Leisure Motivation Scale for Youth Across Gender}

\author{
Yee Cheng Kueh ${ }^{1 *}$, Nurzulaikha Abdullah ${ }^{1}$, Garry Kuan ${ }^{2}$, Tony Morris ${ }^{3}$ and Nyi Nyi Naing ${ }^{4}$ \\ 1 Unit of Biostatistics and Research Methodology, School of Medical Sciences, Universiti Sains Malaysia, Kelantan, Malaysia \\ ${ }^{2}$ Exercise and Sports Science, School of Health Sciences, Universiti Sains Malaysia, Kelantan, Malaysia, ${ }^{3}$ Institute of Sport, \\ Health and Active Living, College of Sport and Exercise Science, Victoria University, Melbourne, VIC, Australia, ${ }^{4}$ Institute for \\ Community (Health) Development (i-CODE), Universiti Sultan Zainal Abidin, Terengganu, Malaysia
}

Measurement equivalence is often assumed across comparison groups, a pervasive problem related to many self-report instruments. Measurement equivalence, also known as measurement invariance, implies that a measure has the same meaning across different groups of people. In this study, we aimed to examine the measurement and structural invariance among gender of the Malay version of the Physical Activity and Leisure Motivation Scale for Youth (PALMS-Y-M). Seven-hundred-and-eighty-three secondary school students (female $=57.3 \%$, male $=42.7 \%$ ) with mean age 14.5 years (standard deviation $=1.25$ ) from Kota Bharu, Malaysia, volunteered to participate in this study and completed the PALMS-Y-M, consisting of 28 items with seven subscales. We conducted the confirmatory factor analysis (CFA) and invariance tests on the seven motives of the PALMS-Y-M model. The hypothesized model consisted of 28 observed items and seven latent variables. We used estimator robust to maximum likelihood, MLR to examine the hypothesized measurement and structural invariance. Measurement invariance was tested for three different levels. We first established the configural invariance model, then we compared the metric invariance model and the scalar invariance model with the less restrictive model. Then structural invariance was tested for factor variance, covariance, and means. Findings provided evidence for full measurement and structural invariance of the PALMS-Y-M in males and females. The final CFA model fit the data well for males [comparative fit index $(\mathrm{CFI})=0.922$, root mean square error of approximation (RMSEA) $=0.048$, standardized root mean residual $(\mathrm{SRMR})=0.050]$ and females $(\mathrm{CFI}=0.922, \mathrm{RMSEA}=0.047, \mathrm{SRMR}=0.053)$. When invariance of both factor loadings and item intercepts holds in PALMS-Y-M, underlying factors consisting of different motives for participating in PA can be meaningfully compared across gender. Accurate and valid measurement of PALMS-Y-M across comparison groups is crucial for future research that involves examining motives to physical activity in different genders and other socio-cultural variables.

Keywords: physical activity, motivation, gender, confirmatory factor analysis, invariance 


\section{INTRODUCTION}

Regular physical activity is important to maintain physical health, fight against obesity, and treat a variety of chronic health conditions. Lack of physical activity causes obesity and complications due to chronic illness, such as coronary heart disease, colon cancer, hypertension, and diabetes (U. S. Department of Health and Human Services, 2008). Moreover, researchers have identified the association between inactivity and different types of cancer, such as breast cancer, and cancer of the colon, endometrium, esophagus, kidney, pancreas, and cervix (Kushi et al., 2006; Lee et al., 2012). Conversely, regular physical activity could contribute to increased mental health and academic performance, lower stress, and depression levels (Nieman, 2002; Rasberry et al., 2011), decrease the risk of coronary heart disease or cardiovascular disease (Williams, 2001), and prolong life expectancy (Lee et al., 2012).

Lack of physical activity among youth has become a major concern in societies. Nearly half of American young people aged between 12 and 21 are not vigorously physical active on a regular basis (U. S. Department of Health and Human Services, 2008). Individuals who were physically inactive during adolescence are also more likely to be inactive in their adulthood (Gordon-Larsen et al., 2004). Physical activity during youth can help protect against many types of health risks in adulthood. Studies have shown that adolescents who actively engage in physical activity, such as aerobic exercise, demonstrated improvement in math skills, cognitive flexibility, improved memory, and creativity (Hillman et al., 2008; Chaddock et al., 2011; Davis et al., 2011). Therefore, youth should be encouraged and motivated to engage in physical activity regularly because there are many immediate benefits for their health.

Motivation has become a key factor in maintaining individuals' physical activity. Research had demonstrated the link between motivation and physical activity (Frederick et al., 1996; Kilpatrick et al., 2005; Wilson et al., 2008; Eisenberg, 2014; Slovinec et al., 2014). Individuals who are intrinsically motivated to undertake physical activity are motivated by factors, including enjoyment, challenge, skill development, and mastery (Frederick and Ryan, 1993; Kilpatrick et al., 2005), whereas individuals who are extrinsically motivated to undertake physical activity are motivated by factors that are not related to the activity itself, including rewards, improved health, and appearance (Frederick and Ryan, 1993; Kilpatrick et al., 2005). Therefore, understanding people's motives for participation in physical activity is crucial given its role in determining whether individuals will initiate and maintain physical activity programs. Physical inactivity is evident in both genders, all socioeconomic, and cultural categories, and at all ages (Weinberg et al., 2000; Molanorouzi et al., 2015). Nonetheless, the low and reducing prevalence of physical activity in younger people is of particular concern (Chaddock et al., 2011; Hu et al., 2015; Abdullah, 2016). More research should be conducted to identify the motives of youth participating in and abstaining from physical activity in order to alter the increasing trend of physical inactivity among youth in many countries.
Reliable and valid measures are important to identify adolescents' motives for participating in any physical activity. Several questionnaires have been developed to measure motivation for physical activity participation, including the Sport Motivation Scale (SMS; Fortier et al., 1995), the Exercise Motivation Inventory (EMI; Markland and Ingledew, 1997), the Exercise Motivation Scale (EMS; Li, 1999), the Motivation for Physical Activity Measure (MPAM; Frederick and Ryan, 1993), the Recreational Exercise Motivation Measure (REMM; Rogers and Morris, 2003), and the Physical Activity and Leisure Motivation Scale (PALMS; Morris and Rogers, 2004). PALMS is the revised and shortened version of the 73-item REMM. It consists of 40 items that provide information about individuals' motives for participation in physical activity. There are eight domains measured in PALMS: mastery, enjoyment, psychological condition, physical condition, appearance, others' expectations, affiliation, and competition/ego. These questionnaires (i.e., SMS, EMI, EMS, MPAM, REMM, and PALMS) were not specifically developed and used to measure motives for participating in physical activity among adolescents and youth. Therefore, a version of PALMS was developed to measure motives for participation in physical and leisure activity among youth. This was stimulated by observations that younger respondents to PALMS had problems responding to items measuring the motive others' expectations. Items on this motive refer to motives associated with being paid to participate and participating to address chronic medical conditions neither of which apply to most adolescents. The others' expectations motive subscale was removed from PALMS. Hu et al. (2015) conducted a study among Chinese schoolchildren using the 35-item, 7-motives version of PALMS that remained, after checking the scale for comprehensibility among 12-15 years old. The model that $\mathrm{Hu}$ et al. (2015) tested was sound, but they removed the least strong item from each motive subscale to produce a shorter questionnaire that they considered to be more suitable for use with this age group. Hu et al. (2015) named the resulting 28-item, 7-motive subscale instrument the PALMS-Youth (PALMS-Y). The "parent" measure, REMM, and the shorter version, PALMS, have been validated in Malay language with adult Malaysiabased samples, and the results indicated sound validity and reliability (Kueh et al., 2017a,b). The validity of PALMS based on confirmatory factor analysis (CFA) was satisfactory with fit indices of RMSEA $=0.041, \mathrm{SRMR}=0.052$ and the composite reliabilities for the motive subscales were acceptable, ranging from 0.67 to 0.85 (Kueh et al., 2017a). Since the PALMS-Y was developed by selecting the strongest items in the PALMS that are relevant to the youth population, we propose that the PALMS-Y will be reliable and valid. Moreover, the simplicity of the items and their meanings are dedicated to measure levels of motives related to physical and leisure activity. Thus, PALMS-Y is suitable to be used for adolescents who engage in physical activity and leisure across a wide range of activity.

Although previous research had confirmed the validity of PALMS using CFA, researchers had never tested for equivalence of PALMS and PALMS-Y among different genders. This means it has not been demonstrated that males and females understand the measure in a similar manner. In addition, research on 
gender differences in motivation indicates that males and females exhibit different primary motives for participation in physical activity (Frederick and Ryan, 1993; Morris et al., 1995; Weinberg et al., 2000). For example, females have consistently rated appearance motives more highly than their male counterparts, whereas males typically score higher on the competition/ego motive than females (Frederick and Ryan, 1993; Frederick and Morrison, 1996; Frederick et al., 1996; Weinberg et al., 2000). It is possible that male and female adolescents would interpret motive items in a motivation questionnaire differently, rather than simply reporting different preferences. For example, the item "to improve body shape" may be interpreted by female as improving body to a slim and possible underweight level that is commonly depicted in entertainment social media, especially in Asian countries, whereas males may interpret improved body shape to be associated with being muscular and strong. In order to make a meaningful comparison between genders, we need to demonstrate that the PALMS-Y is valid and invariant among gender, when measuring the motives of male and female adolescents for participation in physical activity. Measurement invariance is a prerequisite for demonstrating that constructs are comparable across groups (Brown, 2006; Wang and Wang, 2012). Without knowing whether the measure used is invariant across groups of interest, researchers cannot be certain whether observed differences represent genuine differences between those groups or whether they result from differences in interpretation. Thus, it is necessary to examine whether similarities and differences across genders derived, when using PALMS-Y to measure motives, are meaningful.

Until the development of the PALMS-Y and its testing in a Chinese adolescent population, there has been no questionnaire that specifically measures motives for participation in physical and leisure activity specifically in youth. Thus, development and testing the invariance of PALMS-Y has a significant implication for its use in research and health practice in identifying the motives of youth or adolescents for participating in physical and leisure activities. Adolescence is a highly complex transition period from childhood to adulthood. This period is characterized by major biological, physiological, and psychological changes (Lerner et al., 2003), and increased divergence between males and females in physical characteristics, behavior, and brain volume development (Lenroot and Giedd, 2010). Demonstrating measurement invariance of PALMS-Y between males and females, will allow future researchers, health professionals, and physical educators to use this measure confidently irrespective of the gender of adolescents or youth under examination. In the present study, we aimed to validate and confirm the measurement invariance of the Malay version of the PALMS-Y (PALMS-Y-M) among males and females.

\section{MATERIALS AND METHODS}

\section{Participants}

All participants were Malaysian secondary school students. Participants all spoke, read, and wrote in Malay. The participants' age ranged from 13 to 17 years. They were enrolled in government-funded secondary schools in Kota Bharu, Malaysia during the data collection period. A total of 783 secondary school students (male $42.7 \%, n=334$, female $57.3 \%, n=449$ ) participated in this study. The mean age of the participants was 14.5 years [standard deviation $(\mathrm{SD})=1.25$ ], and their ethnicity comprises Malay (57.3\%), Chinese (41.3\%), Indian $(0.3 \%)$, and others (1.1\%).

\section{Measures}

In the present study, data were collected using a form to gather demographic details and information about physical and leisure activities and the PALMS-Y-M questionnaire.

\section{Demographic/Physical and Leisure Activities Information}

Several demographic and physical and leisure activity questions were included in a form. These questions included personal attributes of the participants (i.e., age, gender, and ethnicity), the sport or physical and leisure activities participants were involved in, and the duration (in minutes or hours) per week of pursuing the activities.

\section{Physical Activity and Leisure Motivation Scale-Youth-Malay (PALMS-Y-M)}

The PALMS-Y-M consists of 28 items with seven subscales measuring different type of motives for participating in physical and leisure activities. The seven motives are mastery, enjoyment, psychological condition, physical condition, appearance, affiliation, and competition/ego. Each motive (subscale) of PALMS-Y-M consists of four items. Examples of items and their respective subscales are: to get better at an activity (mastery), because it's interesting (enjoyment), to better cope with stress (psychological condition), because is helps maintain a healthy body (physical condition), to define muscle, look better (appearance), to do activity with others (affiliation), and because I perform better than others (competition/ego). The 28 items and their respective subscales can be found in Appendix. The response format for all the items is a 5-point Likert scale rated from 1 (strongly disagree) to 5 (strongly agree), higher scores reflect that participants experience a higher level of that motive for participating in physical and leisure activities. PALMS-Y-M is the short version of Malay version of PALMS (PALMS-M) and PALMS-M has been previously validated in a Malaysia-based sample. In the present sample, the internal consistency for each motive subscale based on Cronbach's Alpha was as follows: 0.77 (enjoyment), 0.77 (mastery), 0.76 (competition/ego), 0.73 (affiliation), 0.85 (appearance), 0.79 (physical condition), and 0.83 (psychological condition).

\section{Procedure}

Ethics approval for this study was obtained from the Universiti Sains Malaysia Human Research Ethics Committee. Participants and their parents were provided with a research information sheet and written informed consent was obtained from parents prior to the study. All subjects gave written informed consent in accordance with the Declaration of Helsinki. Permission to conduct data collection in schools was also obtained from the 
Ministry of Education Malaysia, District Office of Education Kota Bharu, and the school principals from the selected secondary schools in Kota Bharu, Kelantan.

A cross-sectional study design was employed in the present study. A cluster sampling method was applied by randomly selecting three out of 48 secondary schools in Kota Bharu, Kelantan. The schools' principals were contacted for the study. Among the selected secondary schools, all the students who were available during the data collection period were invited to participate in the study. The students were briefed regarding the study and were asked to obtain written consent from their parents or guardians, if they agreed to participate in the study. Those who volunteered to participate in the study completed the demographic form and the PALMS-Y-M questionnaire and returned them to the researcher. A total of 858 questionnaires were distributed to students, and the response rate was $93.2 \%$ with 800 questionnaires returned to the researchers. However, 17 questionnaires were not completed fully or appropriately, so there were 783 usable questionnaires with complete answers for data analysis.

\section{Data Analysis}

Data analysis was conducted using Mplus 8 (Muthén and Muthén, 1998-2012). There were no missing data in the final dataset. The responses to all 28 items are ordered from 1 (strongly disagree) to 5 (strongly agree). The assumption of multivariate normality was not met based on Mardia multivariate skewness and kurtosis tests of fit $(p<0.001)$. Therefore, an alternative estimator robust to maximum likelihood (MLR; Muthén and Muthén, 1998-2012) was used to examine the measurement model.

The hypothesized measurement model consists of seven latent variables (factors) and 28 observed variables (items or indicators). The factor structure of the hypothesized measurement model was tested in CFA. The fit of the measurement model to the data was evaluated by several fit indices. These fit indices were as follows: the comparative fit index (CFI) and the Tucker and Lewis index (TLI), with the desired value of more than 0.92 , the root mean square error of approximation (RMSEA), with the desired value of less than 0.07 , and the standardized root mean residual (SRMR), with the desired value of less than 0.08 (Hair et al., 2010). The cut off points of the fit indices were taken based on recommendations from Hair et al. (2010) for sample sizes more than 250 and number of observed variables between 12 and 30. The present study on PALMS-Y-M consisted of a sample size of 783 and 28 observed variables, the 28 items of PALMS-Y-M. The Chi-square and its degree of freedom (df) were reported along with other fit indices, although a significant $p$-value can be expected with large sample size (Hair et al., 2010). Factor loadings of 0.40 and above, with significant $p$-values, standardized residuals, and modification indices (MI), were used to locate any problematic items that contributed to misfit to the data (Wang and Wang, 2012). Additional parameters, such as residual covariances among items, were added in the respecification models based on MI values and after consideration of meaningfulness of adding the covariances among the identified items.
Measurement invariance of the scale's items across gender was tested based on published guidelines for establishing measurement invariance of models (Muthén and Muthén, 19982012; Wang and Wang, 2012; Byrne, 2013). We conducted hierarchical tests for invariance of measurement parameters. First, we examined the configured invariance model or pattern invariance, which imposes no equality restrictions on model parameters, including gender in this study. This is a necessary condition for testing invariance by comparing it with other invariance models based on fit indices. Second, we examined the weak invariance model or metric invariance. In this model, the factor loadings are treated as invariant across gender. This ensures that the measures are considered to be on the same scale across gender for making valid comparisons. Third, we examined the strong invariance model. This model imposes invariance on both factor loadings and item intercept across gender. This is to ensure the underlying factors can be compared across gender. Fourth, we examined the strict invariance model, which requires the factor loadings, intercepts, and residual variances to be invariant. This is to examine whether the variances of the regression equations for each item are invariant across gender.

Once the measurement invariance was established, we investigated the invariance of structural parameters. First, we examined the invariance of factor variance and factor covariance to determine whether the relationships between underlying factors remained unchanged in different genders. Then we examined the factor mean invariance to test the factor mean differences between male and female samples. Non-invariance of the structural parameters does not indicate a problem with the measure being studied; it indicates heterogeneity among the comparison groups (Wang and Wang, 2012).

Evidence of invariance between the less restrictive model (e.g., configural invariance model) and more restrictive model (e.g., weak measurement invariance models) were based on recommendations from the literature (Cheung and Rensvold, 2002; Chen, 2007; Wang and Wang, 2012; Kimber et al., 2015). A value of the change in CFI ( $\Delta$ CFI) smaller than or equal to 0.01 indicates that the hypothesis of invariance should not be rejected. For $\triangle$ TLI and $\triangle$ RMSEA, the critical values are 0.01 and 0.015 , respectively. The Chi-square difference test was also reported for each comparison.

\section{RESULTS}

\section{Descriptive Statistics for the Sample by Gender}

The main physical and leisure activities reported by the 13- to 17 -year-old males and females in the sample included jogging, cycling, badminton, basketball, taekwondo, netball, and wushu. Table 1 shows means and SDs for demographic variables and the seven motives for participating in physical activity by gender. Males reported a larger number of physical activity sessions per week than females, and their sessions were also longer than those of females, indicating that males undertook considerably more physical activity than females during a typical week. 
TABLE 1 | Means and standard deviations (SD) for demographic variables and motives for participation in physical activity by gender.

\begin{tabular}{|c|c|c|c|c|}
\hline Variables & Males $(n=334)$ Mean $(S D)$ & Females $(n=449)$ Mean (SD) & $t$-statistics $(\mathrm{df}=781)$ & $p$-value \\
\hline Age, years & $14.62(1.41)$ & $14.42(1.13)$ & 1.94 & 0.053 \\
\hline Number of session of physical activity per week & $2.88(1.94)$ & $2.10(1.31)$ & 6.70 & $<0.001$ \\
\hline Duration per session in minutes & $65.26(55.25)$ & $48.55(45.68)$ & 4.63 & $<0.001$ \\
\hline \multicolumn{5}{|l|}{ Motives for participating in physical activity: } \\
\hline Enjoyment & $3.96(0.69)$ & $3.79(0.72)$ & 3.33 & $<0.001$ \\
\hline Mastery & $3.96(0.65)$ & $3.76(0.65)$ & 4.67 & $<0.001$ \\
\hline Affiliation & $3.71(0.72)$ & $3.48(0.73)$ & 4.30 & $<0.001$ \\
\hline Appearance & $4.15(0.68)$ & $4.18(0.65)$ & -0.66 & 0.509 \\
\hline Competition/ego & $3.41(0.79)$ & $3.06(0.72)$ & 6.60 & $<0.001$ \\
\hline Physical condition & $3.96(0.73)$ & $3.75(0.72)$ & 3.93 & $<0.001$ \\
\hline xsPsychological condition & $3.91(0.72)$ & $3.90(0.75)$ & 0.43 & 0.669 \\
\hline
\end{tabular}

\section{Measurement Model PALMS-Y-M}

The hypothesized measurement model (hypothesized model) for PALMS-Y-M for the whole sample, including both genders, consists of seven factors with 28 items, which is four items in each factor. The test of this model (Model-1) did not result in a good fit to the data $(\mathrm{CFI}=0.905)$. Model-1 was reestimated after each respecification based on MI and with adequate empirical support. These modifications of Model-1 included adding residual covariances on items Q1 with Q2, Q9 with Q10, and Q10 with Q15. The final respecified model (Model2) fit the data well based on several fit indices ( $\mathrm{CFI}=0.924$, RMSEA $=0.046$, SRMR $=0.048$ ).

Baseline models for males (Model-4) and females (Model-6), after respecification, reflect a satisfactorily good fit to the data based on several fit indices (Model-4: CFI $=0.922$, RMSEA $=0.048$, SRMR $=0.050$; Model 6: CFI $=0.922$, RMSEA $=0.047$, SRMR $=0.053)$. Similar, but not completely identical, baseline models were identified for males and females. Baseline models for males and females included adding two residual covariances (items 1 and 2, items 6 and 8 ) and six residual covariances (items 1 and 2, items 10 and 15, items 9 and 10, items 22 and 27, items 19 and 21, items 6 and 11), respectively. The standardized factor loadings for each factor within the male and female models are illustrated in Table 2.

\section{Factor Correlational Structure}

Table 3 details the correlational structure of the seven factors of the PALMS-Y-M based on standardized covariance values for males and females. The standardized covariance values for males ranged from 0.52 to 0.93 and for females they ranged from 0.39 to 0.92 . High standardized covariance values between some factors were expected. For example, latent factor covariances between Enjoyment and Mastery were high (0.92) for both males and females because these two latent factors both reflect the higherorder factor of intrinsic motivation, which is consistent with previous study using the "parent" scale, REMM (Rogers, 2000, unpublished).

\section{Measurement and Structural Invariance}

The two baseline models had the same seven factors, and we found that all 28 items fell into their hypothesized factors (motives). These two baseline models were then integrated into the configural invariance model, with the same number of factors and the same pattern of fixed and free factor loadings, but no equality restrictions were imposed on any parameter across genders. The configural invariance model fit the data well (see Table 4). This configural model was then used to compare against the more restrictive measurement invariance (i.e., weak measurement invariance) model that we examined next.

The first more restrictive model, the weak invariance model, fit the data well (see Table 4). Changes of CFI, TLI, and RMSEA, when the weak invariance model is compared with the configural invariance model, were within acceptable values $(\Delta \mathrm{CFI}=-0.002$, $\Delta \mathrm{TLI}=0, \triangle \mathrm{RMSEA}=0$ ). This indicates that the metric of factor scores was invariant across gender. In other words, the items used to estimate the factor loadings have the same meaning for males and females. The next restrictive model, the strong invariance model also fit the data well (see Table 4). The second more restrictive model, which constrained the factor loadings and item intercept to create the strong invariance model, resulted in the demonstration of strong invariance $(\triangle \mathrm{CFI}=-0.005$, $\Delta \mathrm{TLI}=0.002, \Delta$ RMSEA $=0.001)$. This indicates that both factor loadings and item intercept are invariant between genders. The last more restrictive model, which constrained the factor loadings, item intercept, and residual variances, to produce the strict invariance model was then inspected. The changes of the fit indices were within the recommended values $(\Delta \mathrm{CFI}=-0.004$, $\Delta \mathrm{TLI}=0, \triangle$ RMSEA $=0$ ). This suggests that the average item score comparisons are valid between males and females.

Further invariance testing on structural parameters revealed that the factor variance and covariances of the model of PALMSY-M were invariant between males and females in this sample. The structural invariance for the factor variance and covariances model fit the data well based in RMSEA (0.048) and SRMR (0.062). The differences of several fit indices with the less restrictive invariance model (i.e., strong measurement invariance model $)$ are within the acceptable values $(\Delta \mathrm{CFI}=-0.003$, $\Delta \mathrm{TLI}=0.001, \Delta$ RMSEA $=0$ ). In other words, the same relationships between the seven factors measured by the PALMSY-M remain among the two genders. Factor mean invariance (Model-12) was also tested to see whether the mean of each factor was different among male and female samples. Model-12 
TABLE 2 | Standardized factor loadings for final models.

\begin{tabular}{|c|c|c|c|c|}
\hline \multirow[t]{2}{*}{ Factors } & \multirow[t]{2}{*}{ Items } & \multirow[t]{2}{*}{ Standardized factor loading, all samples ${ }^{a}$} & \multicolumn{2}{|c|}{ Standardized factor loading } \\
\hline & & & Male sample ${ }^{b}$ & Female sample ${ }^{c}$ \\
\hline \multirow[t]{4}{*}{ Enjoyment } & Q1 & 0.564 & 0.497 & 0.607 \\
\hline & Q9 & 0.712 & 0.745 & 0.702 \\
\hline & Q18 & 0.779 & 0.776 & 0.783 \\
\hline & Q25 & 0.679 & 0.666 & 0.672 \\
\hline \multirow[t]{4}{*}{ Mastery } & Q2 & 0.658 & 0.619 & 0.681 \\
\hline & Q12 & 0.716 & 0.758 & 0.682 \\
\hline & Q17 & 0.674 & 0.671 & 0.670 \\
\hline & Q23 & 0.661 & 0.690 & 0.602 \\
\hline \multirow[t]{4}{*}{ Competition/ego } & Q3 & 0.568 & 0.560 & 0.505 \\
\hline & Q13 & 0.735 & 0.752 & 0.776 \\
\hline & Q19 & 0.708 & 0.753 & 0.589 \\
\hline & Q21 & 0.654 & 0.680 & 0.515 \\
\hline \multirow[t]{4}{*}{ Affiliation } & Q4 & 0.626 & 0.651 & 0.634 \\
\hline & Q14 & 0.708 & 0.727 & 0.719 \\
\hline & Q22 & 0.535 & 0.526 & 0.405 \\
\hline & Q27 & 0.710 & 0.666 & 0.676 \\
\hline \multirow[t]{4}{*}{ Appearance } & Q6 & 0.744 & 0.679 & 0.790 \\
\hline & Q8 & 0.769 & 0.702 & 0.794 \\
\hline & Q11 & 0.781 & 0.824 & 0.783 \\
\hline & Q20 & 0.756 & 0.735 & 0.770 \\
\hline \multirow[t]{4}{*}{ Physical condition } & Q7 & 0.586 & 0.639 & 0.523 \\
\hline & Q16 & 0.740 & 0.777 & 0.715 \\
\hline & Q24 & 0.692 & 0.691 & 0.685 \\
\hline & Q28 & 0.787 & 0.737 & 0.825 \\
\hline \multirow[t]{4}{*}{ Psychological condition } & Q5 & 0.639 & 0.617 & 0.652 \\
\hline & Q10 & 0.738 & 0.741 & 0.741 \\
\hline & Q15 & 0.738 & 0.806 & 0.689 \\
\hline & Q26 & 0.774 & 0.779 & 0.772 \\
\hline
\end{tabular}

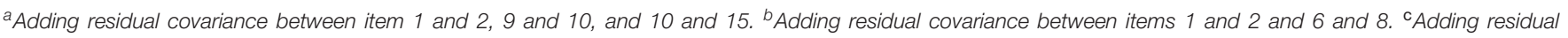
covariance between items 1 and 2, 10 and 15, 9 and 10, 22 and 27, 19 and 21, and 6 and 11 .

fit the data well based on RMSEA (0.049) and SRMR (0.070). When comparing with the less restrictive model (i.e., factor variance and covariance), the differences of several fit indices are within the acceptable values $(\Delta \mathrm{CFI}=-0.007, \Delta \mathrm{TLI}=-0.007$, $\triangle$ RMSEA $=0.001$ ).

\section{DISCUSSION}

The development of the PALMS-Y is an important step in determining individuals' participation in physical activity among adolescents. Among the questionnaires that measure motives for participation in physical activity, PALMS measures a wider range of motives than most other questionnaires. PALMS measures motives across recreational and lifestyle physical activity, as well as competitive sport (Zach et al., 2012). PALMS-Y is a shortened version of PALMS that specifically measures the motives for participation in physical and leisure activity among youth. The Malay language translation of this 28 -item measure, PALMS-Y-M, which was used in the present study, confirmed the multidimensionality of the motives for participation in physical activity. Overall, the seven-factor model of PALMSY-M showed an acceptable fit $(\mathrm{CFI}=0.924$, RMSEA $=0.046$, SRMR $=0.048)$. This is consistent with the previous study on

TABLE 3 | Standardized factors covariance estimated for males and females.

\begin{tabular}{lccccccc}
\hline Latent factors & $\mathbf{1}$ & $\mathbf{2}$ & $\mathbf{3}$ & $\mathbf{4}$ & $\mathbf{5}$ & $\mathbf{6}$ & $\mathbf{7}$ \\
\hline 1. Enjoyment & - & 0.92 & 0.63 & 0.76 & 0.87 & 0.75 & 0.85 \\
2. Mastery & 0.92 & - & 0.75 & 0.69 & 0.93 & 0.89 & 0.89 \\
3. Competition/ego & 0.59 & 0.74 & - & 0.74 & 0.52 & 0.70 & 0.56 \\
4. Affiliation & 0.59 & 0.57 & 0.44 & - & 0.59 & 0.60 & 0.63 \\
5. Appearance & 0.79 & 0.83 & 0.46 & 0.40 & - & 0.87 & 0.84 \\
$\begin{array}{l}\text { 6. Physical } \\
\text { condition }\end{array}$ & 0.65 & 0.68 & 0.41 & 0.39 & 0.66 & - & 0.78 \\
7. Psychological & 0.84 & 0.80 & 0.41 & 0.47 & 0.85 & 0.61 & - \\
condition & & & & & & &
\end{tabular}

Top diagonal $=$ males, bottom diagonal $=$ females. All covariances are significant at $p<0.001$. 


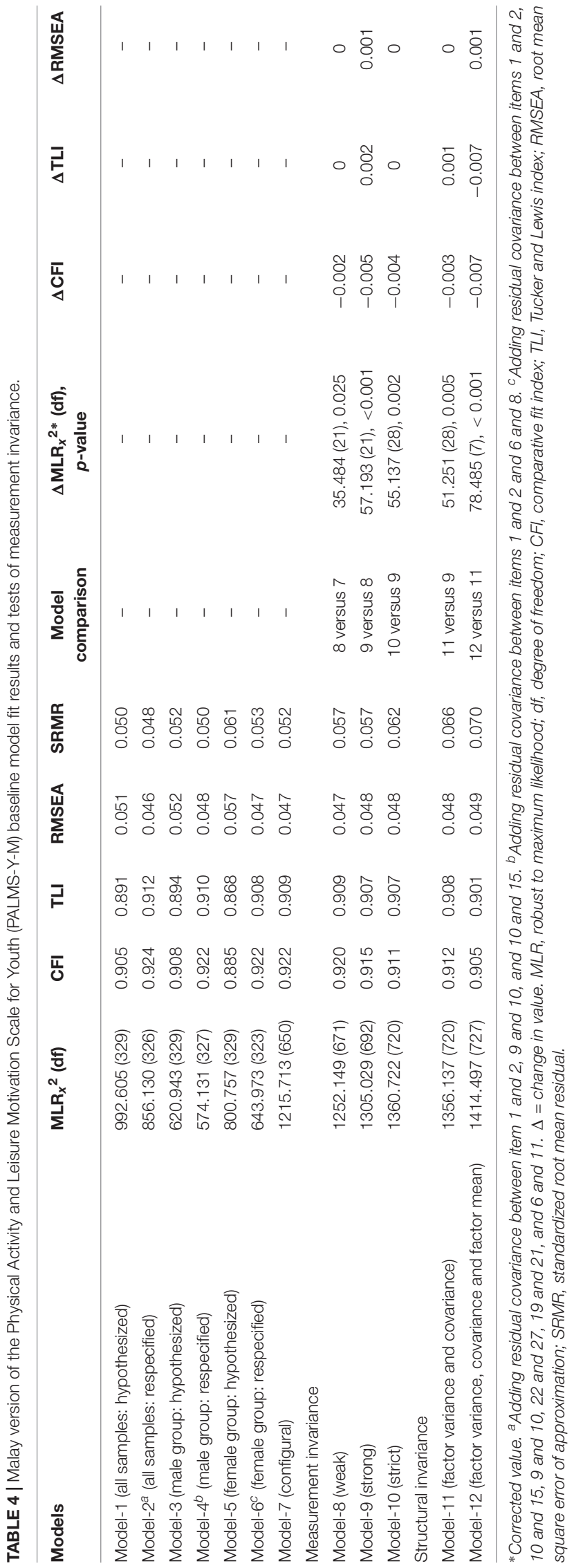

the PALMS-M, where we found that the validity of the adult measure was acceptable based on several fit indices (Kueh et al., 2017a).

The present study provides new insight on measurement invariances of PALMS-Y-M across gender. We tested the measurement and structural invariances of PALMS-Y-M among a youth sample in Kota Bharu, Malaysia. Exploration on the first two levels revealed metric or factor loading invariance (i.e., weak measurement invariance) and scalar invariance (i.e., strong measurement invariance) of the seven-factor model across gender. Metric invariance is important to ensure the measure across multiple groups is considered to be on the same scale, or the factors are measured in the same way in all groups (Vandenberg and Lance, 2000; Meredith and Teresi, 2006; Wang and Wang, 2012). Scalar invariance refers to the item intercept being invariant across multiple groups in the present study. This indicates that none of the groups tends to respond systemtically higher or lower to the items of scales than other groups (Vandenberg and Lance, 2000; Meredith and Teresi, 2006; Wang and Wang, 2012). The present study met both invariance requirements. These results confirm that the two youth samples, male and female, had an equivalent understanding on each of the 28 items in the measure, which is an important prerequisite for making a meaningful comparison between gender on motives for participation in physical and leisure activity.

Researchers have argued that error variance invariance (i.e., strict measurement invariance) is not required for substantive analyses in many disciplines and such invariance is considered unnecessary (Wang and Wang, 2012). However, error variance invariance is crucial when difference of items' reliability across groups is of concern. This is because error variance invariance is considered as invariance of item reliabilities across groups (Schmitt et al., 1984), given that the factor variances are invariant across groups (Vandenberg and Lance, 2000). The present finding on PALMS-Y-M measured across gender met the strict measurement invariance criterion and exceeded the psychometric requirements in invariance testing. Further, invariance tests on the structure of PALMS-Y-M provided convincing results on the invariance of factor variance and covariance. These indicated that the relationships between the seven motives (factors) under study remain unchanged between males and females. The psychometric findings were favorable all along the line with measurement and structural invariance testings suggested in the literature (Meredith and Teresi, 2006; Wang and Wang, 2012). This study also yielded additional information on factor means invariance across gender. According to Wang and Wang (2012), we need to ensure that the scale operates equivalently across comparison groups, but we do not expect that the levels of latent variables remain unchanged among different groups. However, the present study has indicated homogeneity of the mean factors among male and female samples based on the structural invariance for factor variance, covariance, and factor mean.

In the present study, we decided to add covariance between residuals' items within the same factor, as well as from different factors. These modifications on the hypothesized PALMS-Y-M model were decided based on the MI values reported in Mplus 
output and after adequate theoretical support was gathered by the researchers. Two residual covariances involved items from different factors. These were item Q1 [because it's interesting (Factor: Enjoyment)] with Q2 [to get better at an activity (Factor: Mastery)], and item Q9 [because it makes me happy (Factor: Enjoyment)] with Q10 [to get away from pressures (Factor: Psychological Condition)]. Covariance between residuals for items Q1 and Q2 was reasonable, although both items are from different factors. This is because the Mastery and Enjoyment factors are two components of the higher-order factor intrinsic motivation based on previous study (Rogers, 2000, unpublished). Thus, when individuals want to improve their skill in an activity, it is likely that reflects an interest in the activity. Conversely, when individuals are interested in a skill-based activity, it is likely they will want to improve their skill in that activity. These two items could be linked together due to their common background in Intrinsic Motivation. Similarly, with covariance between residuals for items Q9 and Q10, if one removes pressures or escapes them, one should certainly feel happier. Conversely, feeling happy is incompatible with experiencing pressure. Other residuals' covariances added in the baseline models for males and females were within their latent factors. The residuals' covariances for the male sample were items within the factor Appearance (Q6: because it helps maintain a healthy body and Q8: be physically fit) and for the female sample were items within the factor Psychological condition (Q10: to get away from pressures and Q15: because it acts as a stress release), factor Affiliation (Q22: to talk with friends exercising and Q27: to be with friends), factor Competition/ego (Q19: to work harder than others and Q21: to compete with others around me), and factor Appearance (Q6: because it helps maintain a healthy body and Q11: to maintain physical health). These residual covariances were added in the models after consideration of substantive meaningfulness, in order to achieve a better fitting model. This is not suprising. Especially in social psychological research, these parameters can make strong substantive sense, thus, they should be included in the model (Jöreskog and Sörbom, 1993; Cole et al., 2007).

Estimated values of latent factor covariances reflect on their discriminability and, thus, on the extent of the factors dissimilar in PALMS-Y-M. In the present study, some high factor covariances between latent factors are worth noting and discussing. Based on the previous study on the "parent" scale, REMM was created incorporating both theory-based and atheoretical approaches (Rogers, 2000, Unpublished). Rogers' (2000, Unpublished) study was a qualitative study that involved in-depth, semi-structured interviews with exercise participants, to examine their reasons for participation in non-competitive physical activity. The study fit neatly into the framework of self-determination theory (SDT; Deci and Ryan, 1985, 1991), namely intrinsic-extrinsic motivation. In the present study, both the male and female samples indicated high factor covariance between Enjoyment and Mastery. This is expected because both factors reflect intrinsic motivation as reported in Rogers' (2000, Unpublished) study, which fits the theoretical framework of SDT. In addition, strict requirement of zero cross-loadings in CFA or fixing items' factor loading to be zero usually leads to over-estimated factor correlations (Asparouhov and Muthén, 2009). This may also explain the high correlation between latent variables observed in the present study. However, based on previous studies, discriminant validity was found to be satisfactory with correlations between the eight motive factors below the acceptable value of 0.85 (Kline, 2011) for the Malay version of REMM (Kueh et al., 2017b) and PALMS (Kueh et al., 2017a) regardless of gender. We further examined the correlation between factors of PALMS-Y-M in the present study. Based on standardized covariance values, regardless of gender (i.e., combined samples), all values were below 0.85 except for Enjoyment and Mastery (0.92). Although one may propose to combine the factors, which were highly correlated, doing so may cause discrepancy in interpretation of the motives' score in PALMS-Y-M among researchers in the future. Therefore, we proposed that the framework of seven motives of PALMS-Y-M should continue to be interpreted as seven separate domains of motives in adolescent, male and female, samples.

These findings have practical implications for researchers, teachers, physical educators, and health planners who are interested in using the PALMS-Y-M to assess motives for participation in physical and leisure activity in youth. This information can guide practitioners to advise adolescents about the kinds of activities that would satisfy their primary motives, which should lead to long-term participation. Future research needs to be carried out to examine the stability of PALMS-Y and PALMS-Y-M across times by conducting longitudinal studies. Longitudinal CFA models can be applied to examine the stability of cross-time relations of PALMS-Y-M motives and whether the motives change over time. This approach can be extended to the study of factors that influence change by using longitudinal models in the presence of systematic interventions designed to enhance specific motives. In addition, Malaysia is a multicultural country with different types of ethnic groups, including Malay, Chinese, Indian, and the aboriginal. Thus, it would be interesting to examine measurement invariance of PALMS-Y-M among different cultures to ensure the measure is equivalent among different cultural groups in Malaysia.

We acknowledge that self-report survey data is subject to response bias, which may decrease the accuracy of the data provided by the participants. Besides, based on impression management processes, participants may answer the questions so that their responses would make them look good. We bore these response biases in mind during data collection in the present study. Thus, we constantly encouraged and reminded the participants to respond honestly to all questions related to their motives for participation of physical and leisure activities. Also, we assured them of confidentiality, stressing that their answers would not be seen by their teachers, and their responses would not have any effect on their academic performance.

\section{CONCLUSION}

The present study provided evidence of the validity of PALMSY-M and suggests that the measure demonstrated measurement invariance (i.e., configural, weak, strong, and strict) and 
structural invariance (i.e., factor variance, covariance, and mean). These findings provided new information that the PALMS-Y$M$ items were perceived similarly between males and females in this sample from Kota Bharu, Malaysia. Future research on motives for participation among youth can employ the PALMSY-M to examine motives for engaging in any form of physical activity and leisure activities, interpreting their responses within the seven-factor framework of subscales, and making meaningful comparisons across gender.

\section{AUTHOR CONTRIBUTIONS}

YK, GK, and NA developed the concept and design of the study. YK, GK, and NA conducted the study, participated in data collection, analyzed, and interpreted the data. YK and NA

\section{REFERENCES}

Abdullah, N. (2016). Structural Equation Modelling of Self-Esteem, Motivation to Physical Activity and Duration of Physical Activity Among Adolescents in Kota Bharu, Kelantan. Master of Science dissertation, Universiti Sains Malaysia, Penang.

Asparouhov, T., and Muthén, B. (2009). Exploratory structural equation modeling. Struc. Equ. Model. 16, 397-438. doi: 10.1080/10705510903008204

Brown, T. A. (2006). Confirmatory Factor Analysis for Applied Research. New York, NY: The Guilford Press.

Byrne, B. M. (2013). Structural Equation Modeling With Mplus: Basic Concepts, Applications, and Programming. New York, NY: Routledge, Taylor \& Francis Group.

Chaddock, L., Pontifex, M. B., Hillman, C. H., and Kramer, A. F. (2011). A review of the relation of aerobic fitness and physical activity to brain structure and function in children. J. Int. Neuropsychol. Soc. 17, 975-985. doi: 10.1017/ S1355617711000567

Chen, F. F. (2007). Sensitivity of goodness of fit indexes to lack of measurement invariance. Struct. Equ. Model. 14, 464-504. doi: 10.1080/10705510701301834

Cheung, G. W., and Rensvold, R. B. (2002). Evaluating goodness-of-fit indexes for testing measurement invariance. Struct. Equ. Model. 9, 233-255. doi: 10.1097/ NNR.0b013e3182544750

Cole, D. A., Ciesla, J. A., and Steiger, J. H. (2007). The insidious effects of failing to include design-driven correlated residuals in latent-variable covariance structure analysis. Psychol. Methods 12, 381-398. doi: 10.1037/1082-989X.12. 4.381

Davis, C. L., Tomporowski, P. D., McDowell, J. E., Austin, B. P., Miller, P. H., Yanasak, N. E., et al. (2011). Exercise improves executive function and academic achievement and alters neural activation in overweight children: a randomized, controlled trial. Health Psychol. 30, 91-98. doi: 10.1037/a0021766

Deci, E. L., and Ryan, R. M. (1985). Intrinsic Motivation and Self-Determination in Human Behaviour. New York, NY: Plenum. doi: 10.1007/978-1-4899-2271-7

Deci, E. L., and Ryan, R. M. (1991). "A motivational approach to self: integration in personality," in Nebraska Symposium on Motivation 1990: Perspectives on Motivation, ed. R. Dienstbier (Lincoln, NE: University of Nebraska Press), 237-288.

Eisenberg, M. H. (2014). The Mediating Role of Internal Motivation on the Longitudinal Influence of Body Satisfaction on Physical Exercise. Ph.D. dissertation, The George Washington University, Washington, DC.

Fortier, M., Vallerand, R., Briere, N., and Provencher, P. (1995). Competitive and recreational sport structures and gender: a test of their relationship with sport motivation. Int. J. Sport Psychol. 54, 24-39.

Frederick, C., and Morrison, C. S. (1996). Social physique anxiety: personality constructs, motivations, exercise attitudes, and behaviours. Percept. Mot. Skills 82, 963-972. doi: 10.2466/pms.1996.82.3.963 drafted the original manuscript. TM and NN provided critical revisions to the manuscript. All authors read and approved the final manuscript.

\section{FUNDING}

This study was supported by a university grant of the Universiti Sains Malaysia (304/PPSP/61313082).

\section{ACKNOWLEDGMENTS}

The authors wish to thank all the study participants and school teachers, who were involved in and facilitated the present study.

Frederick, C., and Ryan, R. (1993). Differences in motivation for sport and exercise and their relations with participation and mental health. J. Sport Behav. 16, 124-146. doi: 10.1186/s12889-016-3407-0

Frederick, C. M., Morrison, C., and Manning, T. (1996). Motivation to participate, exercise affect, and outcome behaviors toward physical activity. Percept. Mot. Skills 82, 691-701. doi: 10.2466/pms.1996.82.2.691

Gordon-Larsen, P., Adair, L. S., Nelson, M. C., and Popkin, B. M. (2004). Five-year obesity incidence in the transition period between adolescence and adulthood: the National Longitudinal Study of Adolescent Health. Am. J. Clin. Nutr. 80, 569-575.

Hair, J. F., Black, W. C., Babin, B. J., and Anderson, R. E. (2010). Multivariate Data Analysis, 7th Edn. Upper Saddle River, NJ: Pearson Prentice Hall.

Hillman, C. H., Erickson, K. I., and Kramer, A. F. (2008). Be smart, exercise your heart: exercise effects on brain and cognition. Nat. Rev. Neurosci. 9, 58-65. doi: $10.1038 / \mathrm{nrn} 2298$

Hu, L., Morris, T., Lu, J., Zhu, L., Zhang, T., and Chen, L. (2015). Development and validation of a youth version of physical activity and lesuire motivation scale (PALMS-Y). Paper Presented at the 14 European Congress of Sport PsychologyTheories and Applications for Performance, Health and Humanity, Bern.

Jöreskog, K. G., and Sörbom, D. (1993). LISREL 8: Structural Equation Modeling With the SIMPLIS Command Language. Skokie, IL: Scientific Software International.

Kilpatrick, M., Hebert, E., and Bartholomew, J. (2005). College students' motivation for physical activity: differentiating men's and women's motives for sport participation and exercise. J. Am. Coll. Health 54, 87-94. doi: 10.3200/ JACH.54.2.87-94

Kimber, M., Rehm, J., and Ferro, M. A. (2015). Measurement Invariance of the WHODAS 2.0 in a population-based sample of youth. PLoS One 10:e142385. doi: 10.1371/journal.pone.0142385

Kline, R. B. (2011). Principles and Practice of Structural Equation Modeling, 3rd Edn. New York, NY: The Guilford Press.

Kueh, Y. C., Kuan, G., and Morris, T. (2017a). The physical activity and leisure motivation scale: a confirmatory study of the Malay language version. Int. J. Sport Exerc. Psychol. doi: 10.1080/1612197X.2017.1321029

Kueh, Y. C., Kuan, G., Morris, T., and Naing, N. N. (2017b). Confirmatory factor analysis of the Malay version of the recreational exercise motivation measure. PERTANIKA J. Soc. Sci. Human. 25, 589-600.

Kushi, L. H., Byers, T., Doyle, C., Bandera, E. V., McCullough, M., Gansler, T., et al. (2006). American Cancer Society guidelines on nutrition and physical activity for cancer prevention: reducing the risk of cancer with healthy food choices and physical activity. Cancer J. Clin. 56, 254-281. doi: 10.3322/canjclin.56.5.254

Lee, I., Shiroma, E. J., Lobelo, F., Puska, P., Blair, S. N., and Katzmarzyk, P. T. (2012). Effect of physical inactivity on major non-communicable diseases worldwide: an analysis of burden of disease and life expectancy. Lancet 380, 219-229. doi: 10.1016/S0140-6736(12)61031-9 
Lenroot, R. K., and Giedd, J. N. (2010). Sex differences in the adolescent brain. Brain Cogn. 72, 46-55. doi: 10.1016/j.bandc.2009.10.008

Lerner, R. M., Jacobs, F., and Wertlieb, D. (eds) (2003). Handbook of Applied Developmental Science: Promoting Positive Child, Adolescent, and Family Development Through Research, Policies, and Programs, Vol. 2. London: Sage Publications.

Li, F. (1999). The exercise motivation scale: its multifaceted structure and construct validity. J. Appl. Sport Psychol. 11, 97-115. doi: 10.1080/10413209908402953

Markland, D., and Ingledew, D. (1997). The measurement of exercise motives: factorial validity and invariance across gender of a revised Exercise Motivation Inventory. Br. J. Health Psychol. 2, 361-376. doi: 10.1111/j.2044-8287.1997. tb00549.x

Meredith, W., and Teresi, J. A. (2006). An essay on measurement and factorial invariance. Med. Care 44, S69-S77. doi: 10.1097/01.mlr.0000245438.73837.89

Molanorouzi, K., Khoo, S., and Morris, T. (2015). Motives for adult participation in physical activity: type of activity, age, and gender. BMC Public Health 15:66. doi: 10.1186/s12889-015-1429-7

Morris, T., Clayton, H., Power, H., and Han, J. (1995). Activity type differences in participation motives. Aust. J. Psychol. 47(Suppl.), 101-102. doi: 10.1186/ s12889-015-1429-7

Morris, T., and Rogers, H. (2004). "Measuring motives for physical activity," in Proceedings of 2004 International Sport Science Congress: Sport and Chance of Life, (Seoul: KAHPERD), 242-250.

Muthén, L. K., and Muthén, B. O. (1998-2012). Mplus User's Guide, 7th Edn. Los Angeles, CA: Muthén \& Muthén.

Nieman, P. (2002). Psychosocial aspects of physical activity. Paediatr. Child Health 7, 309-312.

Rasberry, C. N., Lee, S. M., Robin, L., Laris, B. A., Russell, L. A., Coyle, K. K., et al. (2011). The association between school-based physical activity, including physical education, and academic performance: a systematic review of the literature. Prev. Med. 52, S10-S20. doi: 10.1016/j.ypmed.2011.01.027

Rogers, H. E., and Morris, T. (2003). "An overview of the development and validation of the recreational exercise motivation measure (REMM)," in Proceedings of the 11th European Congress of Sport Psychology: New approaches to Exercise and Sport Psychology: Theories, Methods and Applications, ed. R. Stelter (Copenhagen: University of Copenhagen).

Schmitt, N., Pulakos, E. D., and Lieblein, A. (1984). Comparison of three techniques to assess group-level beta and gamma change. Appl. Psychol. Meas. 8, 249-260. doi: $10.1177 / 014662168400800301$
Slovinec, D., Angelo, M. E., Pelletier, L. G., Reid, R. D., and Huta, V. (2014). The roles of self-efficacy and motivation in the prediction of short- and long-term adherence to exercise among patients with coronary heart disease. Health Psychol. 33, 1344-1353. doi: 10.1037/hea0000094

U. S. Department of Health and Human Services. (2008). Physical Activity Guidelines Advisory Committee Report. Washington, DC: U. S. Department of Health and Human Services.

Vandenberg, R. J., and Lance, C. E. (2000). A review and synthesis of the measurement invariance literature: Suggestions, practices, and recommendations for organizational research. Organ. Res. Methods 3, 4-70. doi: 10.1177/109442810031002

Wang, J., and Wang, X. (2012). Structural Equation Modeling Applications Using Mplus. Chichester: John Wiley \& Sons Ltd. doi: 10.1002/978111835 6258

Weinberg, R., Tenenbaum, G., McKenzie, A., Jackson, S., Anshel, M., Grove, R., et al. (2000). Motivation for youth participation in sport and physical activity: relationships to culture, self-reported activity levels, and gender. Int. J. Sport Psychol. 31, 321-346.

Williams, P. T. (2001). Physical fitness and activity as separate heart disease risk factors: a meta-analysis. Med. Sci. Sports Exerc. 33, 754-761. doi: 10.1097/ 00005768-200105000-00012

Wilson, P. M., Mack, D. E., and Grattan, K. P. (2008). Understanding motivation for exercise: a self-determination theory perspective. Can. Psychol. 49, 250-256. doi: $10.1037 / \mathrm{a} 0012762$

Zach, S., Bar-Eli, M., Morris, T., and Moore, M. (2012). Measuring motivation or physical activity: an exploratory study of PALMS - The physical activity and leisure motivation scale. Athletic Insight 4, 141-152.

Conflict of Interest Statement: The authors declare that the research was conducted in the absence of any commercial or financial relationships that could be construed as a potential conflict of interest.

Copyright ( 2018 Kueh, Abdullah, Kuan, Morris and Naing. This is an open-access article distributed under the terms of the Creative Commons Attribution License (CC BY). The use, distribution or reproduction in other forums is permitted, provided the original author(s) and the copyright owner(s) are credited and that the original publication in this journal is cited, in accordance with accepted academic practice. No use, distribution or reproduction is permitted which does not comply with these terms. 


\section{APPENDIX}

\section{The Physical Activity and Leisure Motivation Scale for Youth (PALMS-Y)}

In responding to the following statements, think of the motives you have for the physical activity you do. Try not to spend time pondering over your responses. There are no right or wrong answers. Indicate how much your motives correspond with each of the statements. In each case $\mathbf{1}$ indicates strongly disagree and $\mathbf{5}$ indicates strongly agree.

\section{TABLE A1 |}

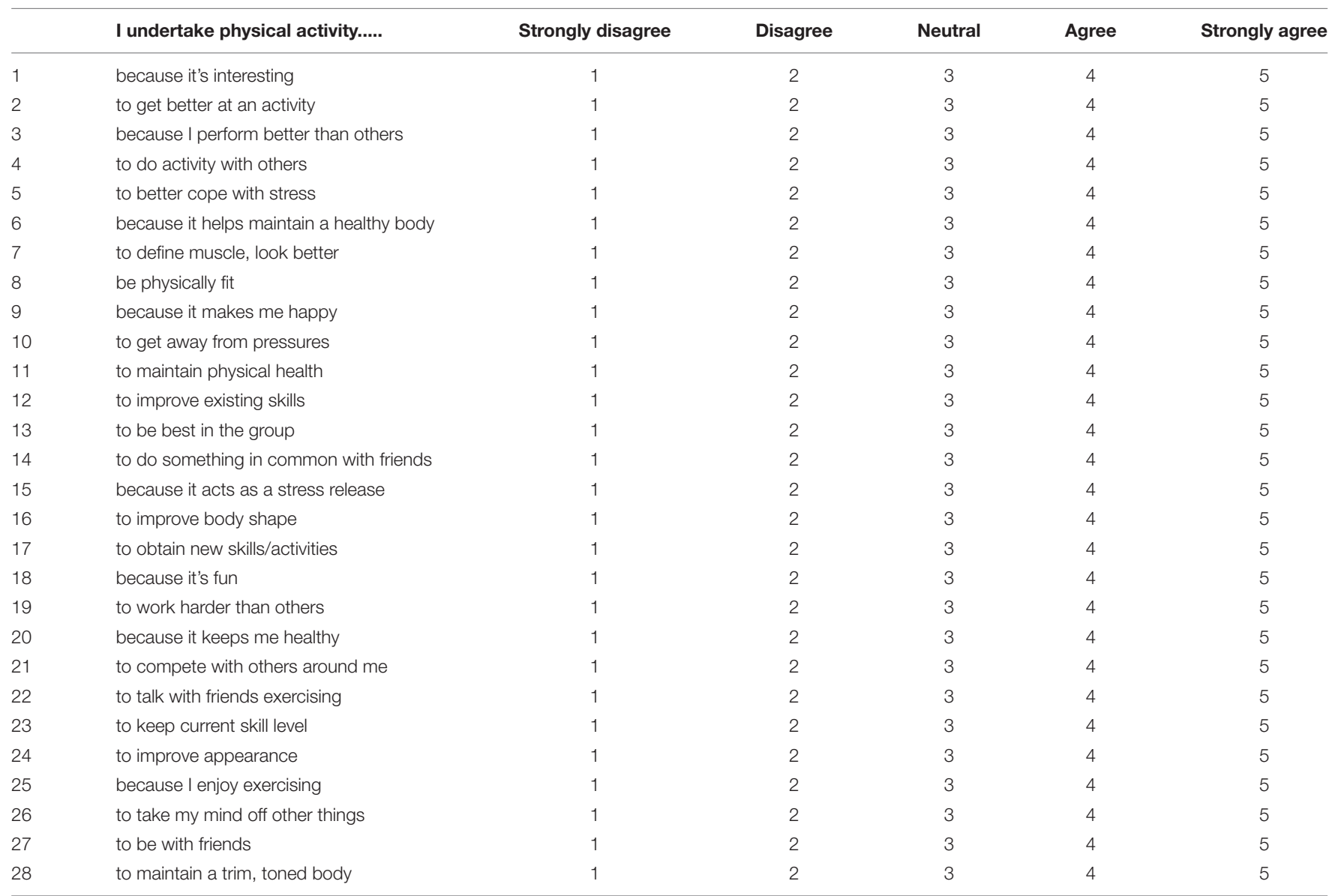

\section{The Malay Version of Physical Activity and Leisure Motivation Scale for Youth \\ (PALMS-Y-M)}

\section{Skala Motivasi Aktiviti Fizikal dan Masa Lapang untuk Belia (PALMS-Y-M)}

Dalam memberi respons kepada kenyataan berikut, fikirkan apa motif anda untuk melakukan aktiviti fizikal yang selalu anda pilih untuk lakukan. Cuba untuk tidak menghabiskan masa yang banyak memikirkan jawapan anda. Tidak ada jawapan yang betul atau salah. Nyatakan sejauh mana motif anda bersetuju dengan setiap kenyataan. Dalam setiap kes, (1) menunjukkan sangat tidak setuju, dan (5) menunjukkan sangat setuju. 
TABLE A2 |

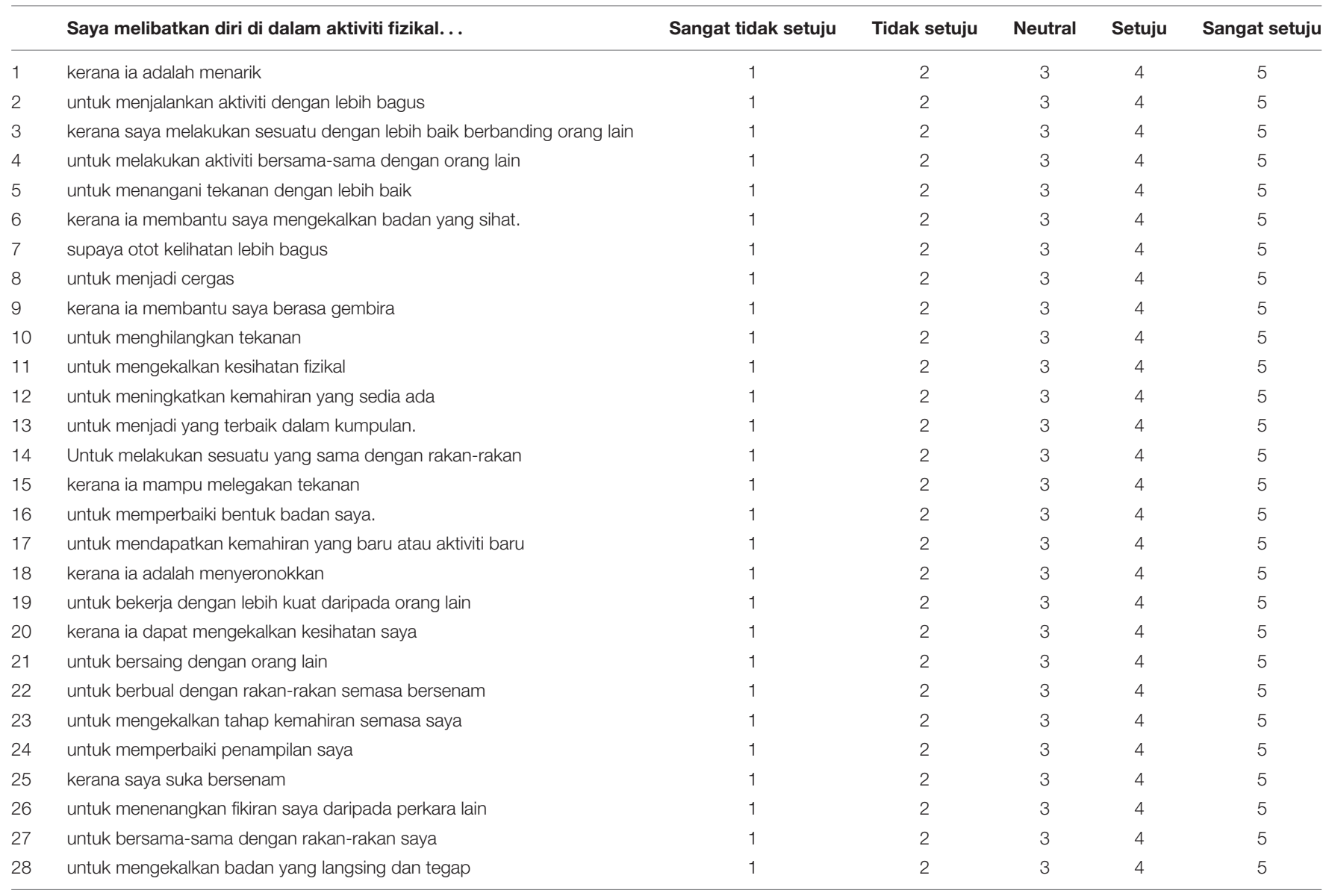

\section{Scoring}

For each motive subscale sum the four scores to produce a total score for that subscale between 4 and 20 and keep the subscales as continuous measures of the seven motives to participate in physical activity and leisure.

Enjoyment items: 1, 9, 18, 25

Mastery items: 2, 12, 17, 23

Competition/ego items: $3,13,19,21$

Affiliation items: $4,14,22,27$

Appearance items: 6, 8, 11, 20

Physical condition items: 7, 16, 24, 28

Psychological condition items: 5, 10, 15, 26 